\title{
Three-Dimensional Heat Transfer Analysis and Optimized Design of Actively Cooled Strut for Scramjet Applications
}

\author{
Fengquan Zhong ${ }^{1}$, Tongying Chen $^{1}$, Xuejun Fan ${ }^{1}$, Lihong Chen ${ }^{1}$, Xinyu Chang ${ }^{1}$ \\ 1. State Key Laboratory of High Temperature Gas Dynamics, Institute of Mechanics, Chinese Academy of Sciences, \\ Beijing, 100190 People's Republic of China
}

In this paper, a numerical analysis coupling heat transfers of the combustor internal flow, the coolant flow and the strut wall is developed and applied for the optimization of strut cooling using aviation kerosene as coolant at flow conditions corresponding to the combustor entrance condition for Mach 6 scramjet flight. The coupling procedure is tested and proven to be an efficient method of being capable to obtain the converged temperature and heat transfer solutions of the cooled strut within a few iteration steps. Four cooling designs with varied diameter, length and position of the cooling channels are investigated and their improvements on fuel injection and mixing are also verified compared to the wall injection. The kerosene-cooled strut (Strut4) is tested in a Mach 2.5 supersonic tunnel with inlet total temperature and total pressure of $1900 \mathrm{~K}$ and $1.45 \mathrm{MPa}$ respectively for 60 seconds. The damaged part in the upper leading edge of the strut is observed, which is consistent with the result obtained by the numerical analysis.

\section{Nomenclature}

$\mathrm{h}_{1}=$ heat transfer coefficient of the combustor flow

$\mathrm{h}_{2} \quad=$ heat transfer coefficient of the coolant flow

$q_{w} \quad=$ wall heat flux

$\mathrm{T}_{\mathrm{r}} \quad=$ recovery temperature of the combustor flow

$\mathrm{T}_{\mathrm{w}} \quad=$ strut wall temperature

$\mathrm{T}_{\mathrm{f}} \quad=$ fuel (coolant) temperature

$\mathrm{T}_{\text {ref }} \quad=$ reference temperature

$\Delta y^{+} \quad=$ grid spacing in the wall unit

\section{Introduction}

The penetration height of fuel from the wall injection in a supersonic combustor of scramjet is generally low, leading to insufficient fuel/air mixing and low combustion efficiency. A strut assembly with fuel channels built inside has been widely used to guide the fuel to inject at a relatively high position from the wall and to increase the fuel mixing and combustion ${ }^{[1,2]}$. Using strut for fuel injection can significantly increase the combustion efficiency and optimize heat release of reaction especially for large-scale scramjets. The strut, however, inevitably endures a harsh thermal environment due to aerothermodynamic and reaction heating in supersonic combustor. For example, at flight Mach number of 6-7, typical values of the wall heat flux and the total temperature at the entrance of the isolator are $0.5 \mathrm{MW} / \mathrm{m}^{2}-1 \mathrm{MW} / \mathrm{m}^{2}$ and $1600 \mathrm{~K}-2100 \mathrm{~K}$ respectively ${ }^{[3-5]}$. Without thermal protection, the currently used high temperature metals or alloys are not reliable for long-run hypersonic flight operations. Hence, it is necessary to protect the strut by means of active cooling. One of the effective ways is to use onboard fuel to cool the strut before it is injected into the combustor. To achieve high cooling effectiveness, the flow and heat transfer 
characteristics of the fuel through the cooling channels and optimization of the cooling structure are imperative to be studied.

In this paper, a numerical method coupling heat transfers of the strut, the coolant flow and the combustor flow was developed and used for the optimization of cooling. The coolant is the aviation kerosene and the flow condition at the combustor entrance corresponds to Mach 6 scramjet flights. Cooling structures with varied channel size, position and length were investigated and a preliminary optimization of strut was obtained. The performance of fuel injection of the optimized strut was also studied and compared to the wall injection, significant improvements of fuel penetration and mixing were observed.

\section{FLUID/SOLID HEAT TRANSFER COUPLING}

As shown in Fig. 1, the fuel enters the cooling channel and cools the structure before being injected. Therefore, the strut cooling is a complicated process that couples convective heat transfer of the scramjet internal flow, heat absorption of the coolant flow and heat conduction through the strut. The complexity of the problem is further increased if aviation kerosene used as coolant since thermophysical and heat transfer properties of kerosene would change significantly as its temperature rises ${ }^{[6,7] .}$ Considering linearity of heat conduction in the wall, a fully coupled fluid/solid heat transfer problem can be simplified into a decoupled iteration procedure based on solving alternately the internal flow, the coolant flow and the strut wall. The iteration procedure is illustrated in Fig. 2. Instead of iterating to try to match temperature and heat flux directly at the fluid/solid interface, a mixed boundary condition in the form of $\left.\frac{\partial T}{\partial n}\right|_{w}=h\left(T_{w}-T_{r e f}\right)$, governed by the local heat transfer coefficient $h(\vec{x})$ of both the internal hot flow and the coolant flow was used. Details of methodology of the fluid/solid coupling and a mathematical proof of the uniqueness of solutions of the wall temperature can be found in a previous work of the author ${ }^{[8]}$. The iteration procedure by using heat transfer coefficient as the coupling parameter is proven to be very efficient and converged temperature and heat transfer solutions of the cooled strut can be achieved within 2-3 iteration steps as discussed in the next section.

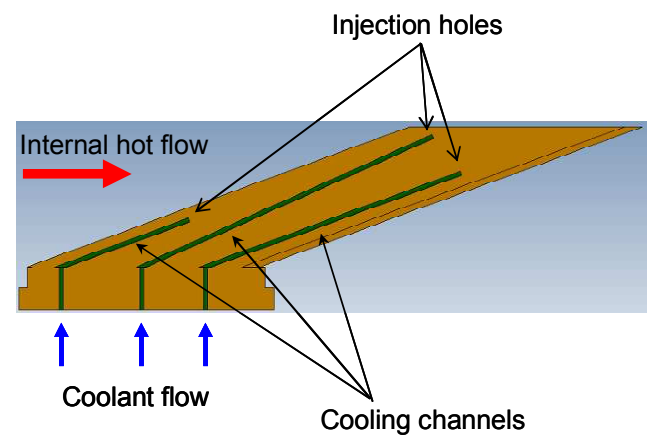

Fig. 1 Sketch of the strut with cooling 


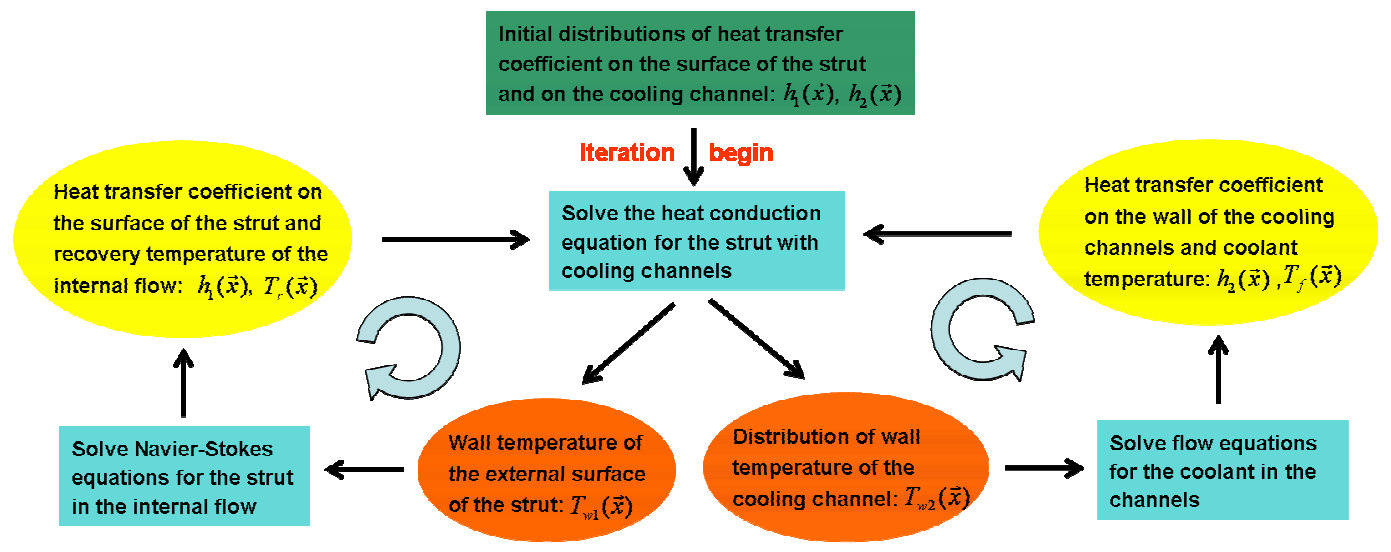

Fig. 2 Flow chart of the iteration process for the heat transfer analysis of the strut with cooling

\section{NUMERICAL METHODS}

For the internal flow, Navier-Stokes equations are solved via control volume method with SST $k-\omega$ turbulence model. The convective terms are calculated with $\mathrm{AUSM}^{+}$flux splitting and MUSCL scheme and the viscous terms are approximated by a second-order central scheme. The minimum grid spacing in the wall direction $\left(\Delta y^{+}\right)$is kept less than one for accurate calculation of the wall heat flux. Grid dependency and turbulence model dependency of the numerical solution was investigated. The present mesh size for the internal flow is $2,600,000$, which has been verified to be good enough for the calculation.

The one-dimensional mass, momentum and energy equation with a 10-species surrogate for China No. 3 aviation kerosene ${ }^{[3,7]}$ are solved to obtained the flow properties of the kerosene along the cooling path. The convective heat transfer of the coolant is determined with correlation formulas based on the experimental results of heated kerosene flow at supercritical pressures ${ }^{[7,9]}$. The 3 -dimensonal heat conduction equation is solved to obtain the distribution of wall temperature and heat flux of the strut with cooling effect.

Fig. 3 (a) gives the calculated heat transfer coefficient defined as $h_{1}=\frac{q_{w 1}}{T_{r}-T_{w 1}}$ along the external surface of the strut. The incoming flow conditions are listed as follows: Mach number is 2.5 , total temperature is $1650 \mathrm{~K}$ and the total pressure is $1.3 \mathrm{MPa}$. Reynolds number based on the incoming flow conditions and the distance from the combustor entrance to the strut is $4 \times 10^{6}$. Fig. 3 (b) shows the contours of Mach number along the strut in a $x-y$ plane through the center line of the strut and in a horizontal x-z plane on the top of the strut respectively. As shown in Fig. 3 (a), the maximum of heat convection occurs in the sharp leading edge of the strut, indicating the front part of the strut is the primary and the critical cooling region.

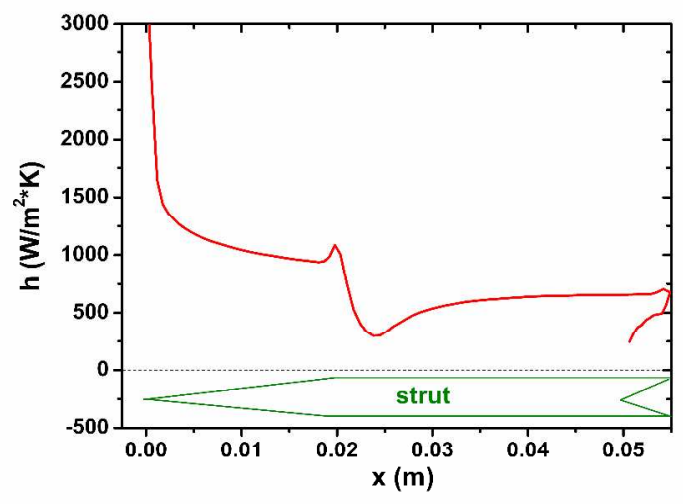

Fig. 3 (a) Distribution of heat transfer coefficient $h_{1}$ along the strut 


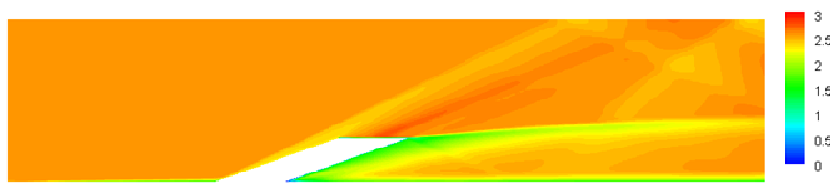

$x-y$ central plane

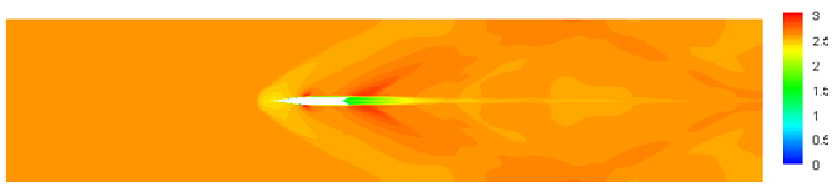

a $\mathrm{X}-\mathrm{z}$ plane

Fig. 3 (b) Contours of Mach number around the strut in a Mach-2.5 supersonic flow

Distributions of the temperature along the leading eage of the cooled strut at ditterent iteration steps as indicated in Fig. 2 are shown in Fig. 4. As shown in the figure, the temperature difference between the second, the third and the fourth steps is very small, proving a fast convergence of the iteration procedure. Fig. 5 gives the change of the heat transfer coefficient $h_{1}$ at different iteration steps and a fast convergence is also found.

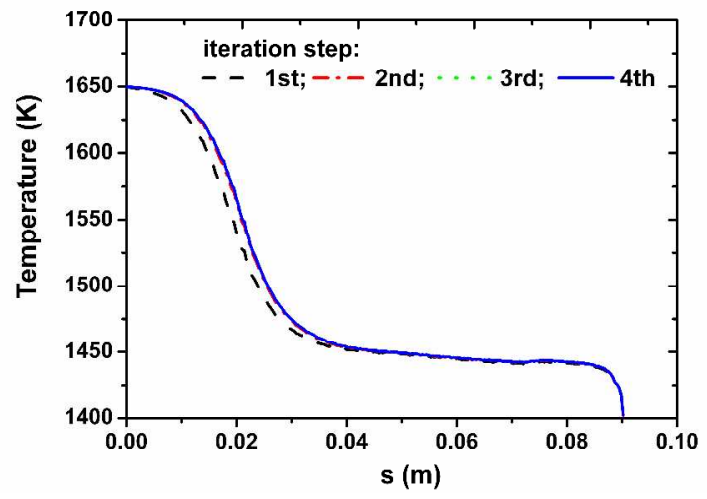

Fig. 4 Distribution of the wall temperature at the leading edge of the strut at varied iteration steps

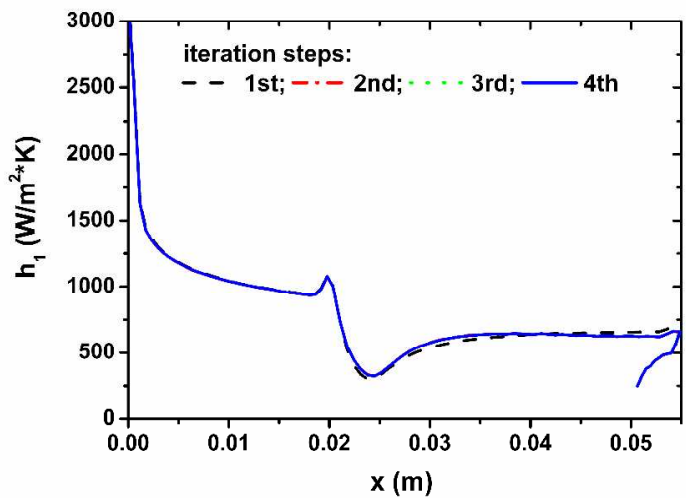

Fig. 5 Distribution of the heat transfer coefficient $h_{1}$ at varied iteration steps 


\section{OPTIMIZATION OF THE STRUT COOLING}

The basic configuration of the strut has a height of $33 \mathrm{~mm}$, a thickness of $5 \mathrm{~mm}$ and a seep back angle of $70^{\circ}$ as shown in Fig. 3. Ni-based Superalloy is chosen as the material for its good mechanical properties at high temperatures $(1100 \mathrm{~K} \sim 1200 \mathrm{~K})$. Four designs of cooling channels with varied diameter, position and length are studied. Fig. 6 is sketch of the four cooling configurations. Strut1 has three channels with a diameter of $1 \mathrm{~mm}$, among which, the second channel has a short length. Hence, the two injection holes with a diameter of $0.4 \mathrm{~mm}$ and connected to the 2 nd channel are located at half height of the strut and on each side. The fuel temperature and pressure at the inlet of the channels are $300 \mathrm{~K}$ and $6 \mathrm{MPa}$ respectively. The total mass flow rate of the coolant is $30 \mathrm{~g} / \mathrm{s}$ with $10 \mathrm{~g} / \mathrm{s}$ for each channel. Fig. 7 (a) gives the contours of surface temperature of Strut1. As shown in the figure, temperature of most part of the structure is kept well below $1100 \mathrm{~K}$ except a very small region located at the bottom of the sharp leading edge of the strut.
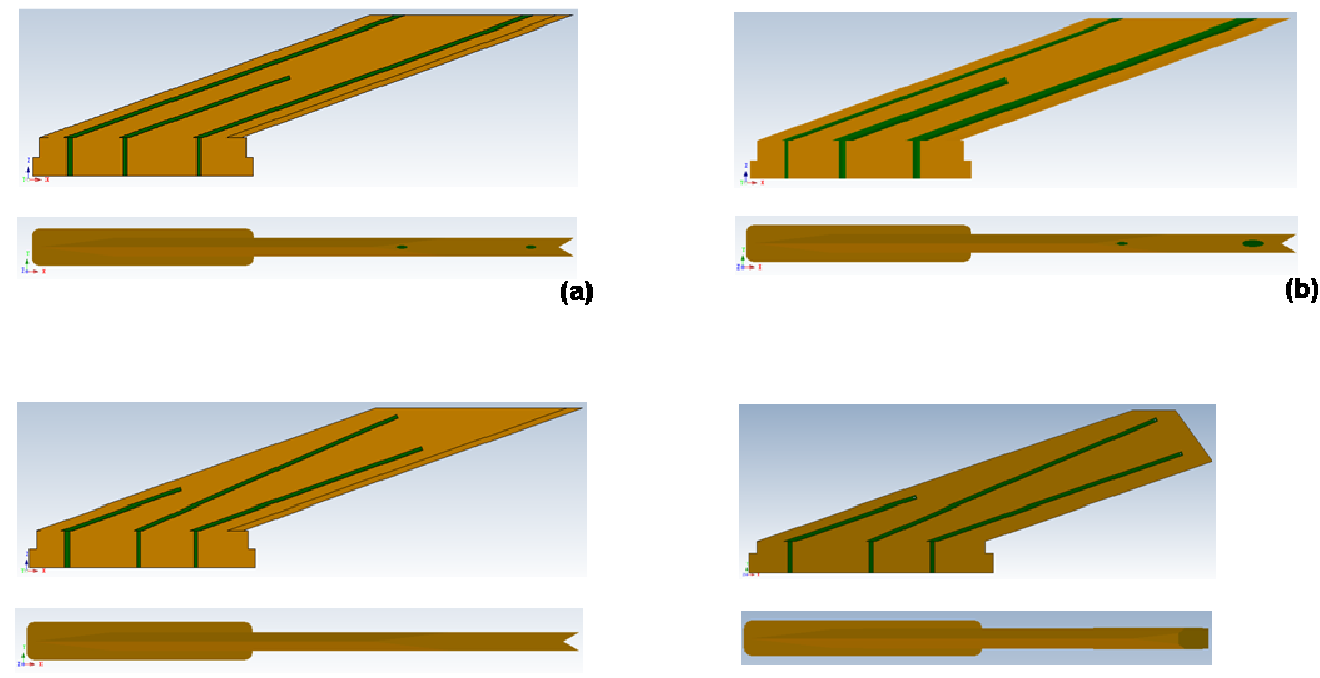

(c)

(d)

Fig. 6 Cooling configurations of strut (a): Strut1; (b): Strut2; (c): Strut3; (d): Strut4

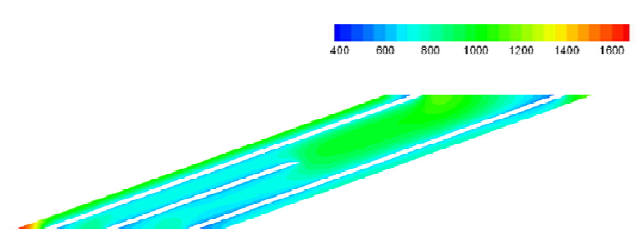

(a)

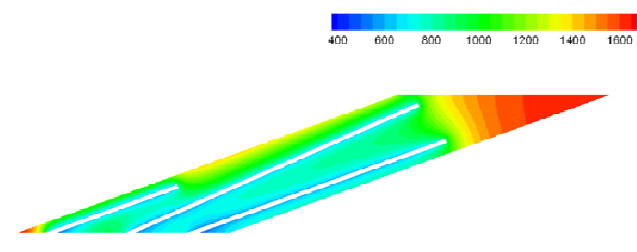

(c)

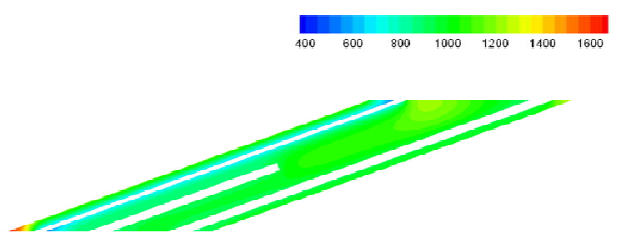

(b)

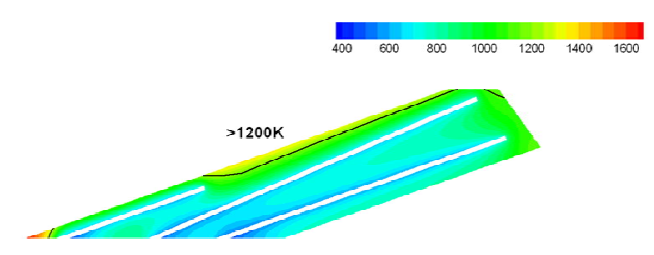

(d)

Fig. 7 Contours of the strut temperature on the x-y central plane (a): Strut1; (b): Strut2; (c): Strut3; (d): Strut4 
For a realistic scramjet with regenerative cooling, hydrocarbon fuel would cool the engine wall before entering strut channels and the fuel temperature at the channel inlet could have risen to a high value. One of the most critical problems for hydrocarbon fuel at high temperatures is carbon deposit and therefore, the channel size must be increased to diminish this effect. For Strut2, diameter of the $2^{\text {nd }}$ and the $3^{\text {rd }}$ channels is increased to $2 \mathrm{~mm}$ and the inlet fuel temperature is increased to $850 \mathrm{~K}$. 'For the $1^{\text {st }}$ channel, the diameter and the fuel inlet temperature are kept as the same as Strut1. The total mass flow rate of kerosene is also $30 \mathrm{~g} / \mathrm{s}$ with $10 \mathrm{~g} / \mathrm{s}$ for each channel. Fig. 7 (b) shows the surface temperature of Strut2. Compared to the result of Strut1, the structure temperature is slightly higher in overall, but most part is effectively cooled with temperatures less than $1200 \mathrm{~K}$. It indicates that kerosene can cool the strut even at such a high temperature, which attributes mainly to the significantly increased Reynolds number and heat transfer coefficient of kerosene flow at high temperatures as discussed in our previous study ${ }^{[7]}$.

As shown in Fig. 6 (c), Strut3 combines performance of both the cooling and the injection. The three channels have different orientation angle and length, resulting in an optimized distribution of the injection holes on each side of the strut. The mass flow rate of kerosene per channel is $30 \mathrm{~g} / \mathrm{s}$ and the inlet temperature and pressure are $300 \mathrm{~K}$ and 6MPa. The surface temperature of Strut3 shown in Fig. 7 (c) has peak values in the rear upper corner of the strut, since there is no cooling in this region and the wall temperature approaches recovery temperature of the internal flow. Based on the result of Strut3, an improvement had been made and the rear upper part of the strut has been cut as shown in Fig. 6 (d). It is found the cutting edge has very tiny effect on the flow field around strut and the total pressure loss due to the strut is quite close for Strut3 and Strut4 (7\% and 6.2\%). Fig. 7 (d) is the surface temperature of Strut4. The relatively high temperature region $(\geqslant 1200 \mathrm{~K})$ in the upper leading edge of the strut is clearly identified in the figure.

\section{PERFORMENE OF FUEL INJECTION AND MIXING}

Performance of fuel injection from Strut4 is numerically studied and compared to that of wall normal injection. Fig. 8 gives the inside mesh structures. The total gird number is 3 million and the minimum grid spacing from the wall is kept less than unity. $\mathrm{C} 12 \mathrm{H} 24$ is used as the surrogate for kerosene due to its similar density and transport properties to China No.3 kerosene. The fuel is injected at temperature and total pressure of $850 \mathrm{~K}$ and $5.5 \mathrm{MPa}$ respectively, representing the fuel exit condition of a cooling system. The contours of Mach number and the mass fraction of the fuel are provided in Fig. 9 (a) and (b). The counter-rotating pair vortices caused by the fuel injection are clearly shown in the figures and their locations are quite far away from the wall as a result of strut injection.

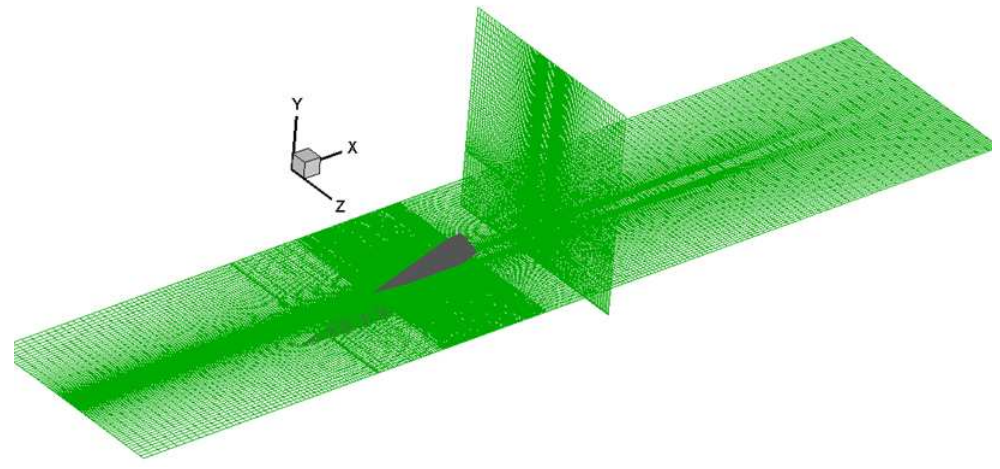

Fig. 8 Meshes for the strut injection 

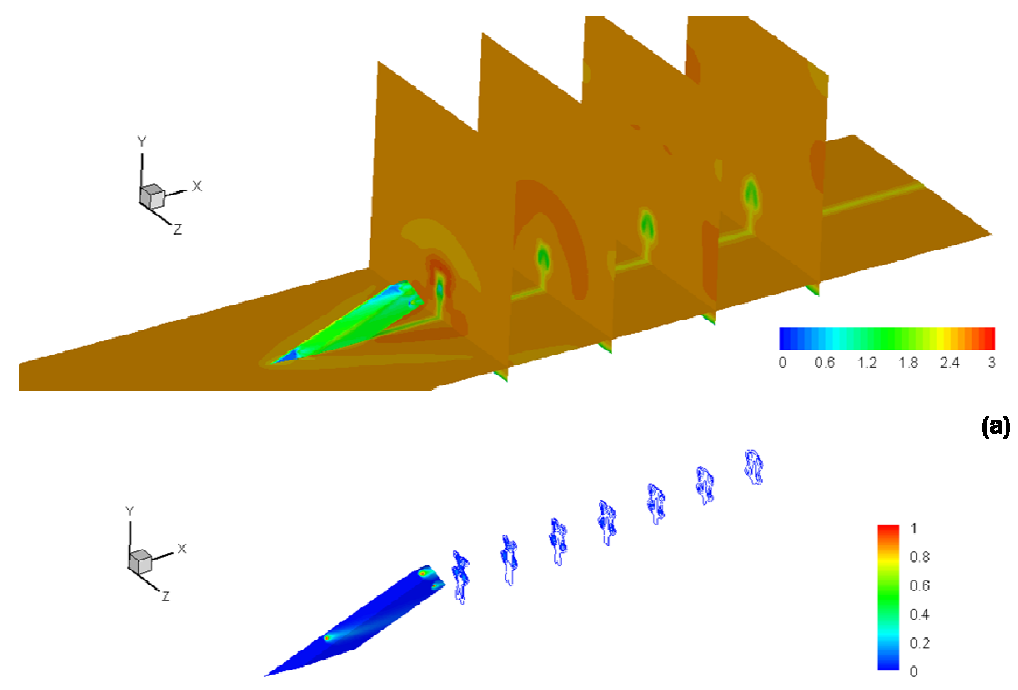

(a)

(b)

Fig. 9 (a): Contours of Mach number; (b): development of the fuel mass fraction along the flow direction

For comparison, the wall-normal injection of $\mathrm{C} 12 \mathrm{H} 24$ at the same fuel temperature, pressure and mass flow rate is calculated. Fig. 10 (a) and (b) give contours of fuel mass fraction on a cross section located 50mm downstream of the injection point. Compared to the wall injection, the strut injection has significant improvements on the fuel penetration and mixing. With fuel injection, the total pressure loss due to the strut is increased from $6.2 \%$ to $7.4 \%$.

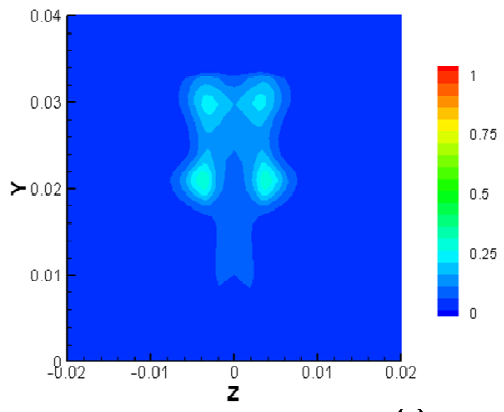

(a)

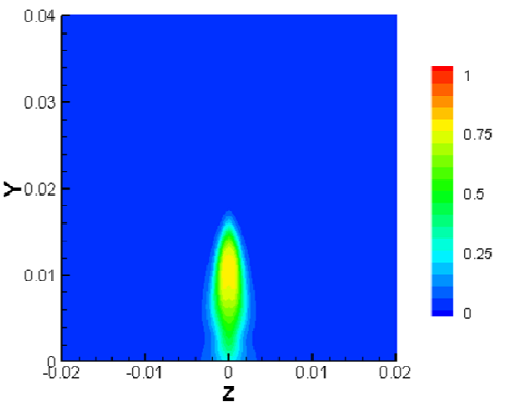

(b)

Fig. 10 Contours of fuel mass fraction on a cross section downstream of the injection (a): strut injection; (b): wall normal injection

\section{EXPERIMENTAL TESTING}

The fuel cooled strut (Strut4) is tested in a long-run supersonic tunnel ${ }^{[5]}$ at a inlet Mach number of 2.5 and at inlet total temperature and total pressure of approximately $1900 \mathrm{~K}$ and $1.45 \mathrm{MPa}$. The mass flow rate of kerosene is $31.5 \mathrm{~g} / \mathrm{s}$, slightly higher than that of the calculation. The testing time is $60 \mathrm{~s}$ and photograph of the strut after the testing is given in Fig. 11. The upper leading edge of the strut is damaged due to the local high temperature in the structure, which is also predicted by the numerical result (Fig. 7 (d)). The relatively large damage is also caused by the operating total temperature of $1900 \mathrm{~K}$, higher than the desired value of $1650 \mathrm{~K}$. The cooling channels and the injection holes survive well in such a harsh thermal environment. Based on the numerical and the experimental results, further improvement on the cooling configuration is being undergone. 


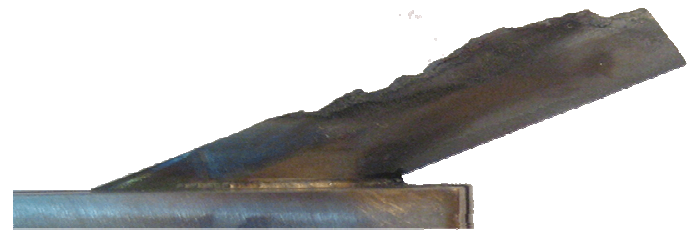

Fig. 11 Photograph of the strut with cooling design of Strut4 after being tested in a supersonic tunnel for 60s

\section{SUMMARY}

In this paper, a numerical analysis coupling heat transfers of the combustor internal flow, the coolant flow and the strut is developed (Fig. 2) and applied for the study and optimization of strut cooling with kerosene fuel used as coolant. The coupling procedure is tested and proven to be an efficient method to obtain the converged temperature and heat transfer solutions of the cooled strut within a few iteration steps (Fig. 4 and Fig. 5). Four cooling designs with varied diameter, length and position of the cooling channels are investigated with the same mass flow rate of kerosene (Fig. 6 and Fig. 7) and Strut 4 is found to be the relatively optimized one and its improvement on fuel injection and mixing is also verified compared to the wall injection (Fig. 7 (d) and Fig. 10). The kerosene cooled strut (Strut4) is tested in a Mach 2.5 supersonic tunnel with inlet total temperature and total pressure of $1900 \mathrm{~K}$ and $1.45 \mathrm{MPa}$ for 60 seconds. The damaged part in the upper leading edge of the strut is observed, which is consistent with the result obtained by the numerical analysis (Fig. 7 (d) and Fig. 11). The cooling channels and the injection holes, however, survive well in the testing.

The numerical analysis is proven to be an effective tool for the design and optimization of cooling of strut. Base on the cooling result of Strut4, further improvement on the cooling configuration is being undergone.

\section{Acknowledgments}

This work is funded by Natural Science Foundation of China under Contract No. 10921062, 10902115 and 11172309. The authors would like to thank Professor Jianguo Li of Chinese Academy of Sciences for her help in this work.

\section{References}

[1] Desikan.S.L.N, Job Kurian.Mixing, "Studies in Supersonic Flow Employing Strut Based Hypermixers", AIAA Paper 2005-3643, 2005.

[2] Peter Gerlinger, Peter Stoll, Markus Kindler, Fernando Schneider, Manfred Aigner, "Numerical investigation of mixing and combustion enhancement in supersonic combustors by strut induced streamwise vorticity", Aerospace Science and Technology, Vol 12, P.159 168, 2008.

[3] Zhong, F-Q., Fan, X-J. and Yu, G., "Heat Transfer Analysis for Actively Cooled Supersonic Combustor", Chinese Journal of Propulsion Technology, Vol.30, No.5, 2009.

[4] Zhong F-Q., Wang X., Chen L-H., Chang X-Y., "Numerical Study of Convective Heat Transfer of Supersonic Combustor", AJCPP 2012-169. 2012.

[5] Li L., Fan X-J., Wang J., "Measurements of Wall Heat Flux and Temperature in a Supersonic Model Combustors", AIAA Paper 2011-5916.

[6] Yang, V., "Modeling of Supercritical Vaporization, Mixing and Combustion Processes in Liquid-Fueled Propulsion System", Proceeding of the Combustion Institute, Vol.28, pp. 925-942, 2000.

[7] Zhong, F-Q., Fan X-J., Yu G., Li J-G., and Sung C-J., "Heat Transfer of Aviation Kerosene at Supercritical Conditions", Journal of Thermophysics and Heat Transfer, Vol.23 No.3, 2009.

[8] Zhong F-Q., Brown G-L., "A 3-Dimensional, Coupled, DNS, Heat Transfer Model and Solution for Multi-hole Cooling", Int. Journal of Heat and Mass Transfer, Vol.50, 2007, pp. 1328-1343.

[9] Zhong, F-Q., Fan, X-J., Yu, G. and Li, J-G.., "Thermal Cracking of Aviation Kerosene for Scramjet Applications", Science in China Series E, Vol.52, No.9, 2009. 